\title{
Gestão da vida e da morte no contexto da COVID 19 no Brasil
}

\author{
Management of life and death in the context of \\ COVID-19 in Brazil
}

\section{RESUMO}

Com a pandemia do coronavírus no Brasil, grupos em situação de vulnerabilidade social têm sofrido mais intensamente processos de marginalização, descaso e invisibilidade. O objetivo principal deste artigo é refletir sobre a gestão da vida e da morte a partir da existência de políticas genocidas que ampliam o sofrimento social em meio a um cenário pandêmico, com subnotificações das mortes, ocultação de cadáveres e a morte social com o cerceamento dos direitos humanos. As discussões empreendidas trazem contextos que convergem para essa realidade a partir de relatos de casos de morte, dor, luto e mistanásia. A realização de entrevistas com mulheres do Maranhão, um dos estados com o maior número de pessoas em situação de pobreza no país, confirma que a pandemia ampliou os espaços de dor e de luto desse grupo em vulnerabilidade social com desemprego, dificuldades financeiras, aumento da sobrecarga de trabalho doméstico e o surgimento de problemas emocionais como ansiedade, medo e depressão

Palavras-chave: Covid-19-Mulheres - Mistanásia - Morte - Vulnerabilidade Social

\begin{abstract}
The coronavirus pandemic in Brazil intensified processes of marginalization, neglect and invisibility experienced by people in situation of social vulnerability. The main objective of this article is to reflect on the management of life and death based on the existence of genocidal policies that increase social suffering amidst a pandemic scenario, with underreporting of deaths, concealment of corpses and social death by violating human rights. The discussion undertaken contextualizes this reality and is based on case reports of deaths, pain, mourning and mysthanasia. Interviews conducted with women from Maranhão - one of the Brazilian states with the highest rates of economic inequality - confirms that some of the pandemic's consequences, such as unemployment, financial difficulties, the increase of housework and the emergence of emotional problems, e.g., anxiety, fear and depression, has expanded spaces of pain and grief for this social vulnerable group.
\end{abstract}

Keywords: COVID-19 - Women - Mysthanasia - Death - Social vulnerability.

* Doutora em Geografia pela Universidade Estadual Paulista, campus Presidente Prudente. Professora do Curso de Turismo da Universidade Federal do Maranhão, campus de São Bernardo, e docente convidada do Programa de Pós-Graduação em Geografia da Universidade Estadual de Londrina (UEL). CV: http://lattes. cnpq.br/2456335844034805

** Doutora em Ciências Sociais pelo Programa de Pós-Graduação em Ciências Sociais da Universidade do Estado do Rio de Janeiro (UERJ). Professora de Sociologia no Curso de Ciências Humanas da Universidade Federal do Maranhão (UFMA), no Campus São Bernardo. Professora colaboradora do Programa de Pós-graduação em Sociologia UFMA (Mestrado Acadêmico) - Imperatriz,. CV: http://lattes.cnpq.br/4472099996822599 


\section{A morte (des) velada}

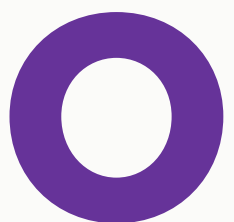

Sars-Cov-2 é um vírus pertencente ao grupo dos coronavírus que em seres humanos causa doença respiratória (Covid-19) e, em casos mais graves, pode levar à morte. A difusão mundial do coronavírus tem mostrado as dificuldades da população em situação de vulnerabilidade social ao verificarmos que as medidas protetivas se distanciam da realidade de grande parte da população - principalmente quando observamos os municípios sem infraestrutura básica, como rede de água, esgoto, energia elétrica e coleta de lixo. Tais fatos dificultam tarefas simples como higienizar corretamente as mãos - uma das medidas essenciais para evitar o contágio da doença. Ao mesmo tempo, o grande número de pessoas que vivem em domicílios pequenos também se torna um impeditivo para o isolamento social, sobretudo, caso haja um diagnóstico positivo por algum membro da família.

Somado a isso, uma parcela significativa da população de áreas vulneráveis é autônoma, implicando em exercer suas atividades laborais no cotidiano das ruas, aumentando o risco de contágio da doença. Nos setores informais e nos serviços pouco valorizados, no município de São Bernardo, no Maranhão/Brasil - local onde trabalhamos - encontramos mulheres que se dedicam ao trabalho doméstico como diaristas e que, por serem chefes de família, não podem abdicar de realizar esses serviços, se arriscando por uma diária de R\$ 35,00 - média paga pelos moradores da cidade pela realização desse serviço, segundo relato da diarista Noélia ${ }^{1}$ que presta serviço para um grupo de professores e funcionários liberais que atuam na cidade. Nesse contexto, está em jogo quem pode e quem não pode se isolar ou ficar em quarentena (Harvey, 2020).

Ademais, diferenças sociais de classe, gênero e raça se interseccionam em processos de exclusão. As mulheres que, em meio a pandemia, se arriscam para garantir a manutenção e "sobrevivência de suas famílias, fazem porque por meio de uma opressão sistematizada, são obrigadas a se sentir supérfluas, ocupando o lugar do inferior desumanizado" (Lorde, 2019, p. 239) por não ter os seus direitos, vontades e desejos respeitados. Assim, a pandemia demarca ainda mais a discriminação com relação à vulnerabilidade que atinge parcelas distintas da população mundial, como destaca Santos (2020). O sul da "quarentena", que segundo o autor vai além de uma demarcação ou fronteira física, relacionando-se a um espaço-tempo político, social e cultural - como assinala Oliveira (2020) ao citar Santos - nem sempre pode escolher seguir as recomendações postas pela Organização Mundial de Saúde (OMS) de prevenção, tais como o distanciamento social e a permanência em casa - medidas essas pensadas para o contexto do Norte global.

As subnotificações dos casos e as estratégias para ocultamento das mortes por decorrência da Covid-19, com laudos médicos atestando morte por Insuficiência Respiratória Aguda Grave, demonstram que "o problema do Brasil é que, na verdade, sua governamentalidade é fundada no massacre dos corpos vulneráveis, na destruição das vidas descartáveis, na invisibilização das mortes" (Oliveira, 2020, p. 382). Ações que atestam que a subnotificação dos

1 O nome citado é fictício, e essa escolha é no intuito de preservar a identidade da interlocutora da pesquisa. 
casos deixou de ser um "problema técnico inerente ao sistema de saúde e passou a ser uma opção política" (Oliveira, 2020, p. 382). Assim, o autor aponta o lugar ocupado pela contagem da população na teoria da biopolítica foucaultiana, sublinhando-a como estratégia de governo das populações.

Por outro lado, em diálogo com o trabalho de Edkins (2011 apud Martínez, 2020), enfatiza o caráter meramente quantitativo do ato de contar estabelecido pelas pesquisas quantitativas e apresentadas por organismos internacionais e por organizações do terceiro setor com objetivo de chamar atenção para atos de desrespeito aos direitos humanos. O fato é que contar nem sempre significa levar em conta, ter em consideração. $O$ caso do Brasil é significativo desse aspecto, com números de mortes se tornando mais volumosos "sob a gestão de um governo negacionista e omisso", nas palavras de Medeiros e Hattori (2020, p. 189).

Nesse cenário de subnotificações e de gestões da morte, é retirado das famílias o direito de enterrar seus mortos e de realizar os rituais fúnebres com dignidade - despedindose de seus entes queridos. É assim que cada um de nós nos tornamos desimportantes no contexto da pandemia (Oliveira, 2020). Contudo, há que se destacar que em um país marcado por desigualdades econômicas e sociais historicamente sedimentadas, acirradas e desnudadas neste contexto de pandemia, alguns são considerados menos importantes que outros.

Como destaca Butler (2018), para ser considerada vida, ela precisa ser enquadrada como tal e, assim, ser passível de luto. Para ser passível de luto, uma vida tem que ser mais do que meramente um organismo biológico, mas possuir condições adequadas de sobrevivência, tais como: moradia, alimentação, saúde (que inclui saneamento básico), dentre outros aspectos. A inexistência desses elementos demonstra que "diante deste processo complexo e circular se cria uma hierarquia sociais e espacial que se mede segundo a capacidade de acesso aos lugares valorizados simbólica e economicamente"2 (Razac, 2015, p. 236).

As notícias que se espalham pelo país, estampando as capas de jornais com enterros e valas comuns, produzem um enquadramento que fala muito mais de morte do que dos mortos (Araújo; Medeiros; Mallart, 2020). São imagens que, na tentativa de imprimir uma narrativa de negligência estatal, em certa medida, acabam contribuindo para fazer desaparecer os mecanismos e dispositivos responsáveis pelas mortes - vinculados a normativas supostamente baseadas em medidas sanitárias. Dentre elas, uma determinava a dispensa do exame médico legal, procedimento conhecido como autópsia, nos casos relacionados à Covid-19, justificandose pelo risco de contaminação. Todavia, essa normativa não define claramente os casos que fogem a esse padrão e que se cruzam nesse contexto de pandemia e de "colapso do sistema de saúde e funerário" (Araújo; Medeiros; Mallart, 2020, p. 4).

O que se tem hoje, no atual governo, é um acirramento das tecnologias de morte, contando com um contexto pandêmico que propicia a ocultação dessas práticas, fazendo desaparecer vivos e mortos. A isso, somam-se os casos de pessoas enterradas no lugar de outras, de corpos trocados ao transitar entre as instituições que atestam e certificam a morte,

2 Citação do trecho original: "Mediante este proceso complejo y circular se crea a la vez una jerarquía, social y espacial, que se mide según la capacidad de acceso a los lugares valorados simbólicamente y/o economicamente". Tradução livre das autoras. 
ampliando a experiência absurda de conviver com alguém que não estando morto legalmente - uma vez que não há a certidão de óbito -, tampouco está vivo. ${ }^{3}$ Permanece fenecendo morto em casa e nos hospitais, com a família esperando que a dignidade chegue ao menos após a morte. Há casos em que, sem coveiros suficientes para a realização do enterro, familiares tiveram que enterrar seus próprios mortos (Araújo; Medeiros; Mallart, 2020).

Em meio a um cenário de vidas ceifadas e histórias fantasmagóricas que vão se sobrepondo a tantas notícias, a categoria de desaparecimento é posta com o intuito de analisar a pandemia no Brasil. Ao utilizá-la não desconhecemos os limites que a apropriação de uma categoria transnacionalizada implica. Porém, queremos destacar que, em um cenário em que as vidas não são enquadradas como vidas, antes mesmo de morrerem, há um compartilhamento do sentimento de que a vida social se perdeu de si mesma* (Gatti, 2017). Existem múltiplas situações definidas pela palavra desaparecimento como: o absurdo, a irracionalidade, a ausência, o vazio, a impossibilidade de representação e paradoxos. A eliminação dos corpos vincula-se à eliminação de qualquer rastro de existência do indivíduo, como documentos e objetos pessoais, ou seja, sua identidade.

Desde as formas contemporâneas de desaparecimento de corpos, a pandemia tem inserido novos elementos ao contexto brasileiro, dentre os quais o medo cotidiano da morte. Como ressalta Oliveira (2020), o número de óbitos em residências quase dobrou em menos de um mês. Esses sentimentos compartilhados de medo e terror frente aos números diários de morte durante a pandemia atestam o profundo abandono que se alastra envenenando as experiências cotidianas no Brasil. Da apatia, considerada necessária para a manutenção mínima das rotinas, das revoltas que angustiam correndo a nossa saúde mental, há que se conviver ainda com declarações de pessoas pertencentes ao governo que destroem esperanças, tornando as vidas, senão materialmente, mentalmente precarizadas. Uma das afirmações feitas recentemente é da diretora da Susep (Superintendência de Seguros Privados), Solange Vieira, ao dizer que "as mortes de idosos por Covid-19 melhoraria a previdência", 5 diminuindo assim o déficit.

Nesse cenário, a complexidade das nuances que surgem na tentativa de definir, delimitar, bem como as ações tomadas para responsabilizar criminal e civilmente os envolvidos, acabam mascarando pontos relacionados a novas formas de desaparecimento não apenas de pessoas vivas retiradas do seu lar pelo Estado, como na ditadura, mas também de corpos mortos. Desse modo, urge a necessidade de uma nova política em que o verbo "contar" ultrapasse o sentido de contabilizar numericamente e passe a ter um sentido de "[...] tomar conta, considerar, se importar, levar ou ter em consideração por alguém"6 (Martínez, 2020, p. 4).

3 BEATRIZ, Rebeca. Homens mortos por Covid-19 em hospital no AM têm corpos trocados e entregues a famílias diferentes. G1 AM, online, 28 set. 2020. Disponível em: https://g1.globo.com/am/amazonas/noticia/2020/09/28/ homens-mortos-por-covid-19-em-hospital-no-am-tem-corpos-trocados-e-entregues-a-familias-diferentesmorreu-duas-vezes-diz-irmao.ghtml. Acesso em: 28 set. 2020.

4 Citação do original: "extrañada por sí mismo". Tradução livre das autoras.

5 LINDNER, Julia; VARGAS, Mateus. Morte de idosos por Covid-19 melhora contas da previdência, teria dito chefe da Susep. O Estado de São Paulo, online, 28 maio 2020. Disponível em: https://economia.estadao. com.br/noticias/geral,morte-de-idosos-por-covid-19-melhora-contas-da-previdencia-teria-dito-chefe-dasusep,70003317874. Acesso em 20 ago. 20. Grifo nosso.

6 Citação do trecho original: "tener en cuenta, considerar, importar, ser de consideración, o tener en cuenta a alguien". Tradução livre das autoras. 
Atualmente, quem morre vira apenas um número na ampla estatística de óbitos. $\mathrm{E}$ virando apenas um número, não se tem identidade, história e família como enfatizam Santos et al. (2020). A verdadeira face de uma estrutura necropolítica, herança de uma sociedade escravagista em que não se parava a cadeia produtiva por conta da morte de escravos, perdura na atualidade quando nos deparamos com a banalidade da morte, como no caso ocorrido recentemente nu uma rede internacional de supermercados, quando um funcionário morreu de infarto e teve o corpo coberto por guarda-sóis enquanto o estabelecimento continuava a operar normalmente. ${ }^{7}$ A população mais pobre e mais vulnerável sofre o descaso e a omissão em diversas instâncias públicas e privadas no seu cotidiano, sem ter os seus direitos respeitados, inclusive, na morte.

\section{Mistanásia: a morte social em situações de vulnerabilidade}

No livro "A mulher dos pés descalços" de Scholastique Mukasonga, escritora tutsi de Ruanda, a autora inicia sua história narrando o desejo de sua mãe de que, quando morresse, suas filhas mulheres cobrissem o seu corpo. Em um tom de súplica e desespero, a mãe de Scholastique implorava que ninguém deveria ver seu corpo descoberto depois de morto. Infelizmente, Mukasonga, que precisou migrar da região onde morava em seu país natal para salvar sua vida, não pôde realizar o pedido. "Mãezinha, eu não estava lá para cobrir o seu corpo, e tenho apenas palavras - palavras de uma língua que você não entendia - para realizar aquilo que você me pediu. E estou sozinha com minhas pobres palavras e com minhas frases, na página do caderno, tecendo e retecendo a mortalha de seu corpo ausente" (Mukasonga, 2017, p. 7).

O receio em forma de súplica presente na fala materna de Stefania Mukasonga se relaciona com a de um interlocutor sulafricano, migrante, relatado pela pesquisadora Kobelinsky (2017 apud Schindel 2020), de que o medo da morte era menor do que o de desaparecer, fato compreensível uma vez que, ao morrer nessas condições, não teria garantia de que receberia um funeral ou mesmo que sua família teria conhecimento de seu paradeiro. Em situações de desaparecimento, muitas são as histórias que surgem, em suas monstruosas faces. Recentemente, devido à troca dos corpos em diferentes estados, familiares de pessoas que morreram com Covid-19 abriram os caixões - medida não recomendada pela OMS devido ao risco de contágio - por receio de não estarem sepultando seus entes queridos. A falta da experiência visual de ter o último contato com o ente querido contribui também para o agravamento da saúde mental, uma vez que fica a esperança de que a pessoa ainda irá retornar. Entretanto, "o novo protocolo sanitário imposto pela pandemia desestruturou essas sequências rituais e desestabilizou as estruturas simbólicas já consolidadas" (Silva, 2020, p. 4).

O luto de Scholastique Mukasonga que não conseguiu dar à mãe um sepultamento como gostaria é compartilhado por milhares de famílias brasileiras desde o início da pandemia

7 PIRES, Breiller. A banalidade da morte num supermercado. El país Brasil, online, 19 ago. 2020. Disponível em: https://brasil.elpais.com/brasil/2020-08-19/a-banalidade-da-morte-a-sombra-dos-guarda-sois.html. Acesso em: 10 ago. 2020. 
do coronavírus, no país que já levou a morte mais de quase 500 mil pessoas8. Nesse processo, os velórios em casos de morte por Covid-19 não são recomendados. O corpo é removido rapidamente e enterrado para evitar a propagação do vírus. Nesse ponto, há uma ruptura dos rituais, pois, o velório é o elemento principal do rito de passagem no Brasil no qual existe a interação social entre amigos e parentes: "Ao falar sobre ele, chorar a sua ausência, tocar e olhar a face sem vida, os vivos se preparam para o enterro, que é o encerramento da convivência física com aquela pessoa, no qual o desaparecimento do corpo atesta a sua transformação em ancestral" (Silva, 2020, p. 3).

Presenciam-se novas formas de despedida e de homenagem aos mortos, inclusive, com cerimônias sendo transmitidas pela internet, fato que se tornou corriqueiro no cotidiano dos moradores do município de São Bernardo, no Maranhão, com o agravamento da pandemia no ano de 2021. Há na cidade dois blogs que se dedicam a cobertura do cortejo fúnebre, Portal Romério Carvalho9 e Blog do Ilder Costa,10 cujo objetivo é propiciar a despedida virtual do ente querido para aqueles que não podem, e nem querem, se arriscar em aglomerações.

Com a pandemia, o tempo do ritual fúnebre, que no nosso país costuma a durar cerca de 24 horas - durando, em alguns contextos, até mais do que esse período, principalmente em cidades interioranas -, teve que ser reduzido, com o caixão velado, impedindo que os familiares das vítimas se despeçam de seus entes queridos, esvaindo ainda mais as experiências que ajudam a passar pelo processo de luto. Esses novos protocolos relacionados às mortes pelo vírus SARS-CoV-2 acabaram por ampliar a dor dessas famílias. Com isso, há uma desestruturação das tradições, destituindo também a identidade do morto. Em vida, também vem ocorrendo um retorno das práticas no tratamento de pessoas enfermas, como foi no passado com as pessoas contaminadas pela peste negra, com quarentena e isolamento social. Processo que torna ainda mais penosa a vida dos moribundos, como pontua Elias (2001). Em tempos de pandemia, também na morte o isolamento e a solidão persistem, na figura representativa do caixão lacrado, evitando o último contato afetuoso com o mundo dos vivos.

Ainda com o processo de vacinação recente no país, o distanciamento social tornouse a principal medida de proteção em massa como uma tentativa de se evitar um colapso do sistema de saúde do Brasil (Santos et al., 2020). Várias cidades do país têm implementado o sistema de bandeiras por cores para alertar sobre o índice de propagação do vírus. De acordo com o número de casos, existem restrições ou liberações de alguns serviços e atividades. No entanto, o isolamento social não é possível para parte da população brasileira, acentuando ainda mais as desigualdades sociais. Nas favelas e comunidades, a pandemia é invisível. Entre becos e corredores apertados, em barracos que abrigam às vezes oito ou dez pessoas, a disseminação do vírus se propaga facilmente. Porém, os mecanismos de desaparecimento de corpos são percebidos na ocultação de números de óbitos que mascaram a realidade. Em maio de 2020, dados levantados pela ONG Redes da Maré apontaram que a covid-19 tinha

8 BRASIL. Ministério da Saúde. Coronavírus Brasil. 2021. Disponível em: https://covid.saude.gov.br/. Acesso em 19 jun. 2021.

9 Blog. CARVALHO, Romério. Portal Romério Carvalho. São Bernardo/MA. Disponível em: https:// portalromeriocarvalho1.blogspot.com. Acesso em: 05 jun. 2021.

10 Blog. COSTA, Ilder. Blog Ilder Costa. São Bernardo/MA. Disponível em: https://www.blogildercosta.com/. Acesso em: 05 jun. 2021. 
matado pelo menos 35 pessoas no Complexo da Maré. No entanto, somente oito óbitos foram contabilizados oficialmente. ${ }^{11}$

Nos últimos sete anos, a extrema pobreza aumentou no Brasil, somando 13,5 milhões de pessoas sobrevivendo com renda mensal per capita de até 145 reais, de acordo com a Síntese de Indicadores Sociais do Instituto Brasileiro de Geografia e Estatística ${ }^{12}$. A pobreza atinge, principalmente, a população preta ou parda, que representa cerca de $70 \%$ dos pobres, somando aproximadamente 38 milhões de pessoas. ${ }^{13} \mathrm{O}$ estado do Maranhão é considerado um dos mais "pobres" do Brasil. De acordo com o último levantamento apresentado com base na Pesquisa Nacional por Amostra de Domicílio (Pnad) ${ }^{14}$, desenvolvida pelo IBGE, relativo ao período entre 2016 e 2017, o estado ocupa o penúltimo lugar no ranking que mede o Desenvolvimento Humano, perdendo apenas para Alagoas. O Índice de Desenvolvimento Humano (IDH) do Maranhão é 0,639, valor considerado de desenvolvimento médio.

A esses dados, destaca-se também um processo de oligarquização da política, que resultou em longos períodos de mandonismos políticos, que conduziram à reprodução de práticas de descaso com os serviços públicos, como apontam Sousa et al. (2011). Os autores também apontam a mortalidade infantil, o trabalho escravo, o analfabetismo e a falta de saneamento básico como agravantes do quadro de vulnerabilidade social. Diante disso, nos questionamos: o que significa ser o estado mais pobre em um país em que a desigualdade social e econômica, estruturante e estruturada, faz parte das realidades locais de maneira generalizada? Em um país cujo neoliberalismo se configura através de uma governamentalização gângster, como aponta Estevéz (2018 apud Oliveira, 2020), em que corpos são sacrificados em nome de um milagre econômico, o que significa habitar a periferia, da periferia, da periferia?

As desigualdades sociais e subalternidades evidenciam a existência de uma classe privilegiada com acesso aos serviços básicos de saúde, possibilidade de trabalhar em modalidade home office, mantendo o distanciamento social e podendo contatar serviços via internet, aplicativos e outros, tem permitido uma quarentena bem menos restritiva do que a população miserável pobre e marginalizada. Ao ter que sair de casa, a população pobre precisa se expor constantemente ao vírus, ao risco de contaminação e da morte iminente a para trabalhar, enfrentando ônibus lotados, encarando horas em filas de banco para resgatar o auxílio emergencial. Mas também se expõe em casa, em seu domicílio de poucos cômodos, que abrigam muitas pessoas sem água encanada para a higienização correta das mãos. A violação dos direitos humanos, ao não possibilitar igualitário acesso aos serviços de à saúde, educação, moradia seja igualitário, cerceia o próprio direito à vida.

Quando se nega a condição de ser e existir do outro, a partir de políticas de Estado

11 SILVA, Eliana Souza; MARINHO, Dalcio. Nas favelas, até a pandemia de coronavírus é invisível. El país Brasil, online, 14 maio 2020. Disponível em: https://brasil.elpais.com/opiniao/2020-05-14/nas-favelas-ate-a-pandemia-decoronavirus-e-invisivel.html. Acesso em: 20 ago. 2020.

12 INSTITUTO BRASILEIRO DE GEOGRAFIA E ESTATÍSTICA. Agência de Notícias. Síntese de Indicadores Sociais. 2019. Disponível em: https://agenciadenoticias.ibge.gov.br/agencia-noticias/2012-agencia-de-noticias/ noticias/25882-extrema-pobreza-atinge-13-5-milhoes-de-pessoas-e-chega-ao-maior-nivel-em-7-anos. Acesso em 19 jun. 2021.

13 FIOCRUZ. Extrema pobreza atinge 13,5 milhões: a pesquisa do IBGE e o papel do Estado na garantia de direitos. 2019. Disponível em: http://cee.fiocruz.br/?q=node/1076. Acesso em: 12 set. 2020.

14 ATLAS DO DESENVOLVIMENTO HUMANO NO BRASIL. Pnud Brasil, Ipea e FJP, 2020. Disponível em: http://www. atlasbrasil.org.br/ranking. Acesso em 19 jun. 2021. 
que não atua para evitar mortes evitáveis, temos o sentido de necropolítica e de necropoder manifestando "[...] interesse da destruição máxima de pessoas e da criação de 'mundos de morte', formas novas e únicas da existência social, nas quais vastas populações são submetidas a condições de vida que lhes conferem o status de 'mortos-vivos'" (Mbembe, 2016, p. 146). Há uma política de "desinvestimento, desinteresse e descompromisso que condiciona a vida e a morte, afetando diretamente os grupos mais vulnerados caracterizando assim, a mistanásia" (Santos et al., 2020, p. 2). Como explicam esses autores, a mistanásia é um neologismo do bioeticista Márcio Fabri dos Anjos, que pode ser compreendido como a morte social, uma morte infeliz, miserável e evitável. O fato de ser evitável evidencia o desprezo pela vida e transforma a naturalidade da morte em um fato moral, cercado de violência, omissão, sofrimento, abandono.

Não se trata da morte de uma pessoa, mas a de muitos que antes da morte física, já estavam mortos socialmente, sendo impelidos de uma vida digna, em uma sociedade que descarta as pessoas, sobretudo, em situação de vulnerabilidade (Ricci, 2017). O conceito de mistanásia demonstra que a morte social pode ainda contribuir para a antecipação da morte física, uma vez que o desamparo estatal leva ao perecimento dos corpos. Santos et al. (2020) propõem o questionamento sobre a dignidade da vida frente a uma situação de total abandono e invisibilidade da população que não possui nem as condições mínimas de saneamento básico e moradia, ao mesmo tempo em que se acentuam as desigualdades cotidianas decorrentes de políticas ditas neoliberais.

\section{O cotidiano das mulheres na pandemia: resistências e (re) existências}

Ao refletir sobre os efeitos da pandemia em situações de vulnerabilidade, tornase necessário trazer à luz algumas concepções basilares sobre o seu entendimento. A vulnerabilidade social não é sinônimo de pobreza, mas contempla um conjunto de fatores multidimensionais que contribuem para que um grupo de pessoas seja mais suscetível a riscos e contingências que deterioram situações de bem-estar e impedem o acesso ao aproveitamento das estruturas de oportunidades que existem na sociedade (Cançado; Souza; Cardoso, 2014). Nesse aspecto, corroborando essa reflexão, é necessário também pontuar que entre membros de uma mesma família em situação de vulnerabilidade social a percepção sobre os efeitos da pandemia se torna distinta, sobretudo, em uma perspectiva de gênero.

A partir de estudos divulgados pelo IBGE, ${ }^{15}$ é possível verificar que as mulheres estudam mais, trabalham mais e ganham menos do que os homens, além de se ocuparem mais dos afazeres domésticos. Em média, o homem trabalha 42,7 horas por semana, enquanto a mulher trabalha 37,9 horas, desconsiderando as horas dedicadas a afazeres domésticos e cuidados com pessoas. A partir da pandemia, as condições de trabalho das mulheres passaram por

15 INSTITUTO BRASILEIRO DE GEOGRAFIA E ESTATÍSTICA. Mulher estuda mais, trabalha mais e ganha menos do que o homem. Agência IBGE Notícias, online, 7 mar. 2018. Disponível em: https://agenciadenoticias.ibge.gov. br/agencia-noticias/2012-agencia-de-noticias/noticias/20234-mulher-estuda-mais-trabalha-mais-e-ganhamenos-do-que-o-homem. Acesso em: 16 fev. 2021. 
transformações, gerando maior sobrecarga. Segundo a Fiocruz, ${ }^{16}$ metade das brasileiras passou a cuidar de alguém nesse período. Das mulheres que possuem emprego, 41\% afirmaram estar trabalhando mais. No entanto, essa realidade não é a mesma para todas. Os dados mostram que as mulheres negras e residentes em áreas rurais assumiram mais responsabilidades de cuidado. Além disso, as mulheres negras parecem ter menos suporte nestas tarefas, ampliando os espaços, sentidos e experiências de dor. Para as que trabalham em home office, o estudo também indica que a jornada dupla igualmente aumentou, sem a ajuda de membros da família nas tarefas rotineiras.

Silva et al. (2020) apontam que a partir de um discurso legitimador dos papéis sociais, a mulher ainda é a figura central no cuidado com os idosos, com os filhos e com os enfermos. Inclusive, chamam a atenção para o fato que mais da metade dos profissionais da área de saúde que trabalha na chamada linha de frente do combate ao coronavírus é composta por mulheres. Para os autores, as vidas das mulheres que vivem múltiplas jornadas de trabalho são afetadas constantemente devido ao sistema capitalista que mantém o lucro a partir da exploração da classe trabalhadora, mesmo em um período em que negros, pobres, trabalhadores, estudantes, tem morrido por conta da pandemia.

Com a adoção de medidas de isolamento social no país, muitas atividades cotidianas foram interrompidas, como creches e escolas que funcionavam como uma rede de apoio às mulheres mães universitárias; além da restrição do contato familiar que impactou a vida principalmente daquelas que contavam com o apoio de mães, tias ou avós para cuidar dos filhos. As medidas de ensino e trabalho remoto passaram a vigorar como uma opção entre muitas famílias no país. No entanto, expuseram ainda mais o quadro de vulnerabilidade social, em que famílias inteiras têm que compartilhar o mesmo aparelho (computadores, notebooks, celulares) para realização de suas tarefas, além da falta de internet em muitos domicílios. A permanência estudantil de mulheres mães universitárias é desafiadora no período pandêmico, pois, há um acúmulo de funções que implica até mesmo na falta de tempo para si mesmas, como apontam Silva et al. (2020).

Essa situação vivida pelas mulheres na pandemia é observada em estudantes da Universidade Federal do Maranhão do campus São Bernardo no interior do estado. Com a suspensão das aulas na primeira quinzena de março de 2020,17 percebeu-se uma ruptura dos laços de sociabilidade entre os alunos e uma ressignificação da sua rotina, resultando em quadros de depressão, tristeza, incertezas e faltas de perspectivas em função de perdas materiais como trabalho e renda. Em uma cidade em que a maioria das pessoas trabalha na informalidade, a universidade, para essas pessoas, é vista como uma oportunidade de sair dessa situação, trazendo perspectivas de conseguir um emprego com carteira assinada e auxiliando os familiares financeiramente.

São Bernardo tem uma população estimada em 28 mil habitantes e localiza-se na

16 FIOCRUZ. Metade das mulheres passou a cuidar de alguém na pandemia, revela pesquisa. Portal Fiocruz, online, 05 ago. 2020. Disponível em: https://portal.fiocruz.br/noticia/metade-das-mulheres-passou-cuidar-de-alguemna-pandemia-revela-pesquisa. Acesso em: $17 \mathrm{fev} .2021$.

17 UNIVERSIDADE FEREDAL DO MARANHÃO. Nota oficial: UFMA diante da situação do COVID-19. Disponível: https://portais.ufma.br/PortalUfma/paginas/noticias/noticia.jsf?id=55882. Acesso em 19 jun. 2021. 
região conhecida como Baixo Parnaíba Maranhense, a leste do Maranhão, que abriga 26 municípios e uma população total de aproximadamente 400 mil habitantes. Mais da metade da população reside em área rural e apresenta baixo índice de IDH. ${ }^{18} \mathrm{Nas}$ últimas décadas, esse território vem sofrendo profundas alterações em função da expansão da soja que colabora para o quadro de marginalização da população rural, gerando conflitos territoriais, especialmente, em comunidades tradicionais (Santos; Arrais Neto; Ferreira, 2009; Costa, 2012).

Do ponto de vista do rendimento médio mensal, os trabalhadores de São Bernardo recebem em torno de 1,5 salários mínimos. Os domicílios não representam a garantia de segurança sanitária para as famílias que nele residem, com apenas $11,1 \%$ deles com tratamento de esgoto adequado. ${ }^{19} \mathrm{Com}$ relação ao abastecimento de água, o atendimento é parcialmente ofertado pela Companhia de Saneamento Ambiental do Maranhão (Caema). Na área urbana, 56\% da população tem acesso ao sistema de água encanada. Na área rural, 47\% da população tem acesso adequado à água por meio de poços coletivos e individuais, segundo o Relatório Final do Plano Municipal de Saneamento Básico e Plano Municipal de Gestão Integrada de Resíduos Sólidos. ${ }^{20} \mathrm{Na}$ situação em que nos deparamos atualmente, que nos impõe a necessidade de novos hábitos de higiene como forma de prevenção da doença, esses dados são sintomáticos de como as consequências das desigualdades abarcam variados aspectos.

A maioria dos alunos é oriunda do Baixo Paranaíba Maranhense, principalmente, de povoados que contam com uma infraestrutura ainda mais precária do que na sede do município. Muitos alunos dependem de transporte público cedido pelas prefeituras para se locomoverem até o campus e enfrentam muitos obstáculos. No primeiro semestre do ano, por exemplo, a região costuma ser assolada por um grande volume de chuvas que alagam as principais vias do município devido à falta de planejamento urbano. Nesse período, é comum os alunos faltarem às aulas devido às dificuldades que os ônibus têm em transitar em trechos não asfaltados e mesmo aqueles que utilizam moto também ficam impedidos de chegar à universidade por conta dos alagamentos. Já na estação seca, no segundo semestre, a temperatura chega facilmente a 40 graus e a sensação térmica aumenta em função da falta de um plano de arborização que implica na escassez de sombreamento nas vias, obrigando os moradores a saírem equipados com guarda-chuvas para se proteger do sol causticante. Aqueles que podem escolher, somente saem de suas casas ao entardecer.

Além da questão da mobilidade, muitos estudantes universitários dependem de bolsas acadêmicas destinadas a grupos em vulnerabilidade socioeconômica, como o programa Foco Acadêmico, ofertado pela UFMA ${ }^{21}$ ou auxílios emergenciais como o Bolsa Família. Como a bolsa não chega a todos, alguns são obrigados a desistir da universidade para ajudar no sustento da família. Para esse grupo estudantil que já enfrenta dificuldades pelo contexto socioeconômico

18 SISTEMAS DE INFORMAÇÕES TERRITORIAIS. Perfil territorial. Baixo Parnaíba-MA. 2015. Disponível em: http://sit. mda.gov.br. Acesso em: 15 mar. 2020.

19 INSTITUTO BRASILEIRO DE GEOGRAFIA E ESTATÍSTICA. Cidades São Bernardo, 2017. Disponível em: https:// cidades.ibge.gov.br/brasil/ma/sao-bernardo/panorama. Acesso em: 20 ago. 2020.

20 SÃO BERNARDO. Relatório Final do Plano Municipal de Saneamento Básico e Plano Municipal de Gestão Integrada de Resíduos Sólidos. Prefeitura Municipal de São Bernardo. 2020 (no prelo).

21 O Programa Foco Acadêmico a partir de seu edital, possibilita que docentes inscrevam projetos de pesquisa para obter bolsa aos estudantes em situação de vulnerabilidade social. A bolsa tem vigência de um ano e um valor de $\mathrm{R} \$ 400,00$. 
em frequentar uma universidade pública, o período da pandemia contribui para acentuar essas fragilidades. Nesse sentido, quando se colocam tantas restrições de acesso aos serviços básicos, tornando ainda mais árdua a vida dos estudantes no Maranhão, a gestão da vida é similar à gestão da morte.

Com relação à pandemia, o estado registrou mais de 300 mil casos de covid-19 e registrou mais de 8 mil mortes. Tal situação contribuiu para que o governo realizasse medidas drásticas de contenção da doença, como o lockdown (bloqueio total), decretado para a capital São Luís com o objetivo de restringir a circulação social. Em São Bernardo, houve a morte de 17 pessoas e mais de 1 mil casos confirmados, segundo dados do governo do estado..22 Ressalta-se que no início, a pandemia era percebida somente a partir das cidades médias e grandes. Com a difusão do vírus pelas cidades pequenas, além das mortes, a doença também ampliou os espaços de dor dos moradores, pois a morte começou a ter o rosto de pessoas conhecidas. Em termos simbólicos, o desaparecimento dos corpos diante dos olhos de família e amigos, retirados pelos agentes funerários rapidamente para se evitar contaminação, remete à mistanásia, à morte social da população vulnerável que já no seu cotidiano vê desaparecer não somente corpos, mas a vida que se finda aos poucos.

No intuito de desvendar a situação de alunas de uma universidade pública federal de São Bernardo em meio a situações de perdas, luto, dor e morte no período da pandemia e seus desdobramentos no cotidiano, foi realizada uma pesquisa com estudantes bolsistas e voluntárias envolvidas em projetos vinculados ao programa Foco Acadêmico com a participação espontânea de seis mulheres. A metodologia utilizada foi grupo focal que se caracteriza por reunir um conjunto de pessoas para discutir temas a partir de sua experiência pessoal, segundo Gatti (2005). Em função da pandemia, os instrumentais metodológicos sofreram adaptações, de modo que as discussões foram realizadas via plataformas virtuais de comunicação. As pesquisadoras se reuniram previamente e elencaram os pontos referentes aos questionamentos que seriam levantados durante os grupos focais. Para dar maior oportunidade de fala às entrevistadas, optou-se pela realização da pesquisa em duas sessões. A primeira realizada no dia 18 de junho de 2020 com um grupo de quatro mulheres, sendo duas discentes do curso de Turismo, uma de Ciências Naturais/Química e uma de Linguagens e Códigos/Música. A segunda sessão ocorreu no dia 25 de junho de 2020 com um grupo de duas mulheres do curso de Ciências Humanas/Sociologia.

Durante a realização da pesquisa, adaptada para o ambiente virtual e com a participação das duas autoras desse artigo, a dificuldade de acesso à internet acabou atrapalhando a interação entre os participantes, uma vez que pontos de debate desenvolvidos nas falas eram interrompidos pelas falhas técnicas e que, por isso, tinham que ser retomados. Nesse sentido, a dinâmica não fluiu como esperávamos, porém, tal fato foi interpretado como representativo das desigualdades com relação ao acesso à internet, ao conhecimento e à informação. Apesar da autorização na utilização dos seus nomes na pesquisa, optou-se por não revelar a identidade das mesmas. Com isso, serão utilizados nomes fictícios.

22 MARANHÃO. Coronavírus. 2020. Disponível em: https://www.corona.ma.gov.brl. Acesso em: 19 jun. 2021 
Na primeira sessão participaram Beatriz, ${ }^{23} 23$ anos, solteira e sem filhos; Luana, 25 anos, solteira e sem filhos; Jessica, 27 anos, solteira e sem filhos e Marisa, 21 anos, casada, sem filhos. Beatriz e Luana são irmãs e moram com a mãe, o padrasto e a irmã de 15 anos, em São Bernardo. Jessica mora com a irmã, o cunhado e a sobrinha em Magalhães de Almeida, município vizinho de São Bernardo. Marisa mora com o marido, dois cunhados e os sogros em Baixa Grande, um povoado de São Bernardo, localizado a $10 \mathrm{~km}$ da sede municipal. Sobre a questão cor/gênero poucas se manifestaram. Luana se autodeclarou branca e Marisa se autodeclarou parda e de gênero feminino.

Sobre a renda familiar, Marisa trabalha na roça com o marido e os sogros e vende esses alimentos na cidade. O trabalho demanda a contratação de pessoas para auxiliá-los nesse processo, mas por conta da pandemia, para evitar aglomeração, optaram por deixar toda a atividade para a família realizar, o que aumentou a carga de trabalho. Para as mulheres, ficou ainda mais árduo, uma vez que também acumulam o trabalho doméstico. Marisa relatou que além da sua própria casa, teve que cuidar da casa da mãe que adoeceu e não conseguia dar conta dos afazeres domésticos.

Com relação à renda mensal, somente Marisa informou que a família recebe em torno de dois salários mínimos. As irmãs Beatriz e Luana não souberam informar, pois a renda maior da casa é a partir de trabalhos informais realizados pelo padrasto como pedreiro que ganha por dia de trabalho; portanto, quando não consegue serviço, não recebe dinheiro. No período da pandemia, a situação se agravou em função da diminuição de oportunidades de trabalho. A família conta com benefícios sociais, como o Bolsa-família ${ }^{24}$ e também conseguiu o auxílio emergencial disponibilizado pelo governo. Jessica relatou que conta com uma renda fixa mensal, pois a irmã é funcionária pública concursada. No entanto, ressalta que com a finalização da bolsa de assistência estudantil ${ }^{25}$ que ganhava, vai precisar procurar emprego para ajudar em casa. A família recorreu ao auxílio emergencial ${ }^{26}$ do governo e o obteve para se manter diante da pandemia. Sobre os afazeres domésticos, Jéssica, Beatriz e Luana relatam que a divisão do trabalho em casa ocorre de forma equitativa, embora o trabalho em casa tenha aumentado nesse período.

Além dessas mudanças no cotidiano, a pandemia também trouxe incertezas às estudantes e problemas de ordem psicológica. Marisa informou que desenvolveu crises de ansiedade nesse contexto. Luana e Beatriz também relataram sentimentos de desânimo,

${ }^{23}$ Apesar do consentimento das entrevistas e uso dos dados, os nomes das nossas interlocutoras presentes neste artigo são fictícios por uma questão ética de escolha ética.

${ }^{24}$ O Bolsa-família é um programa do governo federal que implica na transferência direta de renda às famílias em situação de pobreza e de extrema pobreza. O valor de cada benefício é de $\mathrm{R} \$ 41,00$ e cada família pode acumular até 5 benefícios por mês, chegando a R\$205,00 segundo o site do governo: https://www.caixa.gov.br/ programas-sociais/bolsa-familia/Paginas/default.aspx

25 O processo de seleção das bolsas de assistência estudantil é composto por várias modalidades, sendo elas: bolsa Permanência, bolsa Programa Foco Acadêmico, Auxílio Estudante com Filho(a) e Auxílio Transporte. Os estudantes recebem essas bolsas por um período, sendo que a bolsa permanência é por um período de dois anos, sem a possibilidade de renovação. As demais podem ser renovadas, contudo o estudante tem que passar por uma nova seleção após completar um ano. Em muitos casos esses alunos e alunas não conseguem a renovação da bolsa.

26 Auxílio Emergencial é um benefício federal com objetivo de conceder renda aos trabalhadores informais, microempreendedores individuais (MEI), autônomos e desempregados no período da pandemia. O valor varia entre R\$150,00 a R\$ 375,00 por mês dependendo da composição familiar, segundo o site do governo: https:// www.caixa.gov.br/auxilio/auxilio2021/Paginas/default.aspx 
angústia e medo constante de estarem contaminadas. Jessica relata com maiores dificuldades a falta de perspectiva de retorno à chamada vida normal. Isso vem gerando falta de vontade de realizar atividades rotineiras. Schmidt et al. (2020) corroboram esse entendimento sobre a situação enfrentada pelas estudantes ao relatar estudos que indicam que o medo de ser infectado por um vírus que não tem tratamento até o momento afeta o bem-estar psicológico de muitas pessoas, trazendo sintomas de depressão, ansiedade e estresse.

Na segunda sessão de entrevistas contou-se com Flávia, 40 anos, casada, três filhos e Bárbara, 46 anos, casada, dois filhos. Nenhuma delas se manifestou com relação à cor e gênero ao se apresentarem. Essas estudantes, diferente das entrevistas do primeiro grupo, são oriundas de outros estados do país. A primeira veio de São Paulo, onde conheceu o marido maranhense e optaram por morar no interior do Maranhão. A segunda se deslocou do Rio de Janeiro, com o marido e os filhos, para visitar o irmão que morava no Maranhão; a família não quis voltar mais para o sudeste e Bárbara teve que acatar essa decisão. Com isso, também teve que se adaptar à vida de uma cidade de interior.

Flávia trabalha como auxiliar de professora, na educação infantil, com contrato temporário. A renda maior vinha do marido que conserta máquinas de costuras e é professor de corte e costura. A família tinha um comércio e uma oficina que tiveram que ser fechados em função da pandemia. O serviço do marido também foi afetado diretamente, pois, implicava em aulas particulares que foram canceladas por conta do distanciamento social. No caso de Bárbara, o marido é o único que possui renda em casa e trabalha com manutenção de ar condicionado. Pelo fato de São Bernardo ser uma cidade pequena, muitas pessoas sabem que ele tem doença crônica e, com receio de o receberem em casa, o número de serviços diminuiu drasticamente. Tanto Bárbara como Flávia recorreram ao auxílio emergencial para sobreviver no período, no entanto, o benefício de Flávia foi cortado logo após uns meses devido seu vínculo com a prefeitura.

Com relação às tarefas domésticas, Flávia e Bárbara relataram que houve uma sobrecarga de trabalho em função do aumento de pessoas dentro de casa, fazendo com que utensílios e cômodos se sujem mais rapidamente. Apesar de afirmarem que têm ajuda dos maridos e filhos em casa, relataram que o chamado "trabalho pesado" fica a cargo das mulheres, como lavar e passar roupas. Do ponto de vista das angústias e incertezas diante da pandemia, as estudantes relataram que tiveram crises de ansiedade e tristeza, como retrata Flávia: "[...] tem dia que eu choro muito. Ontem mesmo eu chorei muito, muito. Aí hoje de manhã eu falei assim: 'tenho que acordar melhor amanhã, porque amanhã eu tenho que mostrar que estou bem pras (sic.) meninas, para as meninas não ficarem preocupadas comigo também'. Mas, enfim, cada dia é um processo, a gente não sabe: hoje estamos bem, amanhã a gente não está".

Como salienta Santos (2020), as mulheres são as "cuidadoras do mundo" e, com isso, a pandemia torna mais difícil a vida de mães, filhas, tias, avós, conforme verificado neste estudo de caso A presença também constante da doença e da morte física, seja de vizinhos, parentes ou conhecidos, durante a pandemia, vai minando as condições de existência e resistência frente à acentuação das dificuldades cotidianas e amplia os espaços de dor e luto das estudantes por afetar também as subjetividades, trazendo incertezas e problemas de saúde mental, fragilizando 
corpos e mentes.

\section{Conclusão}

As práticas e os mecanismos de gestão de vida no Brasil minam o acesso a uma vida digna, com as condições básicas de existência como saneamento básico, emprego, saúde, educação e moradia. A insuficiência e ineficiência de políticas públicas que possam reverter essa situação provocam a mistanásia, a morte social do indivíduo que perece no seu cotidiano, tornando-o invisível. A ocultação da causa mortis, no país, praticada intensamente na ditadura, se propaga na pandemia resultando em mecanismos de desaparecimento de corpos que nunca foram considerados vidas, mas apenas números. Nesse contexto, situamos a população em vulnerabilidade social que historicamente já sofre duramente constantes perdas na vida material e nas subjetividades simplesmente por existirem. Com isso, a invisibilidade dessa população é uma estratégia de gestão de vida e morte, parte de um discurso compartilhado por uma parcela da sociedade brasileira e pelo atual governo de que corpos de determinadas pessoas poderiam permanecer mais expostos ao vírus e, por conseguinte, mais expostos à morte (FERNANDES, 2020, p. 8).

Na pandemia, as desigualdades sociais se acentuaram ainda mais para alguns grupos sociais já marginalizados, como: mulheres, pobres e pretos. Grande parte dessa população não pode se isolar para se proteger do coronavírus, ficando em risco iminente de doença e morte. No Brasil, as regiões norte e nordeste são as que apresentam os maiores contextos de vulnerabilidade social. Muitas vidas perecem no esquecimento. Para contribuir com essa reflexão, nos propusemos a realizar entrevistas com estudantes mulheres do interior do Maranhão, que figura como um dos estados brasileiros mais críticos com relação à pobreza da população. Com os relatos sobre o seu cotidiano, as entrevistadas apontaram diversas situações de dificuldade que se intensificaram a partir da pandemia.

Verificamos que em situações de vulnerabilidade social, a pandemia reforça os quadros de desigualdade, marginalização e exclusão, ao mesmo tempo em que a gestão da vida se relaciona à gestão da precariedade pelos moradores da cidade e com os mecanismos de prevenção ao adoecimento pela COVID-19. A vida já era incerta para algumas estudantes, principalmente quem não tinha emprego ou renda fixa familiar. A pandemia acarretou quadros de instabilidade emocional que vão gerando desconforto, conflitos e questionamentos sobre a sobrevivência e existência. Por isso, a gestão da vida e da morte na pandemia torna-se desigual entre os grupos sociais, pois os mecanismos de desaparecimentos de corpos perpassam a morte física e resultam em cerceamento dos direitos humanos.

Se para todas as estudantes da pesquisa, a universidade também representa um caminho de melhoria de vida, a suspensão das aulas provocou uma ruptura na esperança de uma vida socialmente digna. O contexto social em que vivem, em uma cidade com falta de saneamento básico, com serviços de saúde precários e desemprego, somado ao descaso político, falta de investimentos e falta de compromisso com a população em situação de vulnerabilidade social, reflete a materialização da mistanásia, a morte em vida. 


\section{Referências bibliográficas}

ARAÚJO, Fábio, MEDEIROS, Flávia; MALLART, Fábio. As valas comuns: imagens e políticas da morte. Dilemas: Revista de Estudos de Conflito e Controle Social, Rio de Janeiro, p. 1-12, 2020. Disponível em: https://www.reflexpandemia.org/texto-33. Acesso em: 20 ago. 2020. Reflexões na Pandemia, 33.

BUTLER, Judith. Quadros de guerra: quando a vida é passível de luto? Rio de Janeiro, Civilização Brasileira, 2018. 288 p.

CANÇADO, Taynara Candida Lopes; SOUZA, Rayssa Silva de; CARDOSO, Cauan Braga da Silva Cardoso. Trabalhando o conceito de Vulnerabilidade Social. In: ENCONTRO NACIONAL DE ESTUDOS POPULACIONAIS, 19., 2014, São Paulo. Anais [...]. São Paulo: Abep. 2014. Disponível em: http://www.abep.org.br/ abeporgb/abep.info/files/trabalhos/trabalho_completo/TC-1045-499-410.pdf. Acesso em: 23 ago. 2020.

COSTA, Saulo Barros da. Produção de eucalipto no Baixo Parnaíba Maranhense - ordenamento (e conflito) territorial em foco. In: JORNADA DE TRABALHO, 13., 2012, Presidente Prudente. Anais [...]. Presidente Prudente: Unesp, 2012. p. 1-16.

ELIAS, Norbert. A solidão dos moribundos seguido de envelhecer e morrer. Rio de Janeiro: Zahar; 2001. 107 p.

FERNANDES, Adriana. Coronel Vírus chegou. Notas etnográficas sobre a Covid-19 entre vulnerabilizados da cidade do Rio de Janeiro. Sexualidade, Salud y Sociedad - Revista Latinoamericana, 2020. p. 7-34.

GATTI, Bernadete Angelina. Grupo focal na pesquisa em Ciências Sociais e Humanas. Brasília: Líber Livro 2005. 80 p.

GATTI, Gabriel. Prolegómenos. Hacia un concepto científico de desaparición. In: GATTI, Gabriel. Desapariciones. Usos locales, circulaciones globales. Bogotá: Siglo del Hombre-Uniandes, 2017. p. 13-32.

HARVEY, David. A crise do coronavírus é um monstro alimentado pelo capitalismo. In: DAVIS, Mike et al. (org.). Coronavírus e a luta de classes. Brasil: Terra sem Amos, 2020. p. 5-13.

LORDE, Audre. Idade, raça, classe e gênero: mulheres redefinindo a diferença. In: HOLLANDA, Heloisa Buarque (org.). Pensamento feminista: conceitos fundamentais. Rio de Janeiro: Bazar do Tempo, 2019. p. 239-249.

MARTÍNEZ, Maria. Cuentas, registros y rescates: prácticas de conteo (y búsqueda) de víctimas de trata con fines de explotación sexual. Sociología y tecnociencia, Valladolid, v. 10, n. 1, p. 2545, 2020.

MBEMBE, Achille. Necropolítica. Artes \& Ensaios, n. 32, p. 123-151, 2016. Disponível em: https:// revistas.ufrj.br/index.php/ae/article/view/8993/7169. Acesso em:18 fev. 2021.

MEDEIROS, Flavia; HATTORI, Marcia Lika. Apresentação do Dossiê 10: Dispositivos estatais e construção dos mortos. Revista M. - Estudos sobre a morte, os mortos e o morrer, Rio de Janeiro, v. 5, n. 10, p. 188-199, jul./dez. 2020. Disponível em: http://seer.unirio.br/index.php/ revistam/article/view/10784. Acesso em: 17 fev. 2021.

MUKASONGA, Scholastique. A mulher dos pés descalços. São Paulo: Editora Nós, 2017. 160 p. 
OLIVEIRA, Everton. Estamos todos vivos? Ciência, política e precariedade na pandemia de COVID-19. Contemporânea - Revista de Sociologia da UFSCr, São Carlos, v. 10, n. 1, p. 379387, 2020. Disponível em: http://www.contemporanea.ufscar.br/index.php/contemporanea/ article/view/932. Acesso em: 20 jun. 2021.

RAZAC, Olivier. Las nuevas delimitaciones del espacio y Epílogo. In: RAZAC, Olivier. Historia política del alambre de espino. Tenerife: Melusina, 2015. p. 169-244.

RICCl, Luiz Antonio Lopes. A morte social: mistanásia e bioética. Pia Sociedade de São Paulo. Editora Paulus, 2017. 96 p.

SANTOS, Boaventura de Sousa. A cruel pedagogia do vírus. Coimbra: Almedina, 2020. 50 p.

SANTOS, Frednan Bezerra dos; ARRAIS NETO, Crisótomo Andrade; FERREIRA, Leticia Araujo. A expansão da soja no maranhão e suas consequências socioambientais: questões preliminares (1990-2005). In: JORNADA INTERNACIONAL DE POLÍTICAS PÚBLICAS, 4., 2009, São Luís. Anais [...]. São Luís, [s. d.], 2009. p. 1-9.

SANTOS, Roberta Lemos dos Santos et al. Mistanásia hoje: pensando as desigualdades sociais e a pandemia COVID-19. Observatório Covid-19. 2020. Disponível em: https://portal.fiocruz. br/sites/portal.fiocruz.br/files/documentos/mistanasia_hoje-_pensando_nas_desigualdades_ sociais_e_a_pandemia_covid-19_doi_.pdf. Acesso em: 10 ago. 2020.

SCHINDEL, Estela. Deaths and Disappearances in Migration to Europe: Exploring the Uses of a Transnationalized Category. American Behavioral Scientist, online, v. 64, n. 4, p. 389-407, 2020. Special Issue: Deaths at the borders. Revisiting the debate in light of the Euro-Mediterranean crisis.

SCHMIDT, Beatriz; CREPALDI, Maria Aparecida; BOLZE, Simone Dill Azeredo; NEIVA-SILVA, Lucas; DEMENECH, Lauro Miranda. Saúde mental e intervenções psicológicas diante da pandemia do novo coronavírus (COVID-19). Estudos de psicologia, Campinas, v. 37, p. 1- 13, 2020. Disponível em: http://www.scielo.br/scielo.php?script=sci_arttext\&pid=S0103-166X202 00001005018lng=engnrm=iso. Acesso em: 28 set. 2020.

SILVA, Andreia Vicente da. Os "ritos" possíveis de morte em tempos de coronavirus. Dilemas: Revista de Estudos de Conflito e Controle Social, Rio de Janeiro, 2020, p. 1-12. Disponível em: https://www.reflexpandemia.org/texto-50. Acesso em: 17 fev. 2021. Reflexões na Pandemia, 50 .

SILVA, Juliana Marcia Santos; CARDOSO, Vanessa Clemente; ABREU, Kamila Eulálio Abreu; SILVA, Lívia Souza. A feminização do cuidado e a sobrecarga da mulher-mãe na pandemia. Revista Feminismos, online, v. 8, n. 3, p. 149-161, 2020. Disponível em: https://periodicos.ufba. br/index.php/feminismos/issue/view/2137/showToc. Acesso em: 17 fev. 2021.

SOUSA, Salviana de Maria Pastor Santos; PEREIRA, Maria Eunice Ferreira Damasceno; ARAÚJO, Maria do Socorro Sousa; ARAÚJO, Cleonice Correia; BRANDÃO, Selma Maria Silva de Oliveira. A questão da pobreza no maranhão: determinantes e formas de enfrentamento. In: JORNADA INTERNACIONAL DE POLÍTICAS PÚBLICAS, 5., 2011, São Luís. Anais [...]. São Luís: [s./d.], 2011. p. 1-11.

Submetido em: 20 de outubro de 2020

Aprovado em: 18 de fevereiro de 2021 